\title{
CECÍLIA MEIRELES E ISABEL DO PRADO: A CONSTRUÇÃO DE O ROMANCEIRO DA INCONFIDÊNCIA
}

\section{CECÍLIA MEIRELES AND ISABEL DO PRADO: THE CONSTRUCTION OF ROMANCEIRO DA INCONFIDENNCIA}

\section{Claudia Dias Sampaio ${ }^{1}$}

RESUMO: O artigo apresenta a correspondência entre a poeta Cecília Meireles e a amiga e jornalista Isabel do Prado, entre os anos de 1940 e 1950. As cartas mostram anotações sobre a criação de o Romanceiro da Inconfidência e constituem um material valioso de reflexão: sobre a relação entre autobiografia e poesia na obra de Cecília; a escrita das cartas como lugar de construção de sua obra; e a importância das redes de amizades entre escritores para o fortalecimento cultural de uma sociedade.

PALAVRAS-CHAVE: Cecília Meireles. Isabel do Prado. Poesia.

ABSTRACT: The article presents the correspondence between the poet Cecilia Meireles and her friend and journalist Isabel Prado, between the years 1940 and 1950. The letters show notes about the creation of the Romanceiro da Inconfidencia and are a valuable material for reflection: on the relationship between autobiography and poetry in the work of Cecilia; the writing of the letters as a place to build his work; and the importance of friendship networks among writers for the cultural strengthening of a society.

KEYWORDS: Cecília Meireles. Isabel do Prado. Poetry.

\footnotetext{
${ }^{1}$ Doutora em Teoria Literária pela Universidade Federal do Rio de Janeiro (UFRJ).
} 


\section{CECÍLIA MEIRELES E ISABEL DO PRADO: A CONSTRUÇÃO DE O ROMANCEIRO DA INCONFIDÊNCIA}

"Escrevo por precisão de me sentir junto com os amigos"

(Andrade, 1967, p. 549)

\section{CARTAS, POEMAS E AFETOS: A CONSTRUÇÃO DE UMA OBRA}

Uma das intelectuais mais atuantes do século XX no Brasil, Cecília Meireles cultivava com esmero o exercício da correspondência, que manteve com poetas e intelectuais brasileiros e estrangeiros; entre eles Mário de Andrade, Alfonso Reyes, Armando CortêsRodrigues, Alberto de Serpa, Diogo de Macedo, Fernanda de Castro, Maria Vallupi, Augusto Meyer, Isabel do Prado, Gabriela Mistral e Carlos Drummond de Andrade. As correspondências de Cecília já foram fonte de pesquisa para estudos significativos que compõem sua bibliografia crítica, como os de Leila Gouvêa, Valéria Lâmego, Ana Maria Domingues de Oliveira, Jussara Santos Pimenta e Fernando Cristovão ${ }^{2}$.

Neste artigo apresento as cartas dirigidas à amiga Isabel do Prado, escritas no período entre julho de 1941 e junho de 1953. A amizade entre Cecília e Isabel, refletida nessa correspondência, revela os bastidores da concepção de uma das obras de maior envergadura na poesia de Cecília Meireles: o Romanceiro da Inconfidência.

As 77 cartas foram doadas por Isabel do Prado à Fundação Casa de Rui Barbosa, que abriga o arquivo pessoal de importantes escritores brasileiros, e estão acompanhadas de um documento datilografado redigido por Isabel apresentando uma pequena cronologia de sua vida nos anos em que se correspondeu com Cecília, onde também lemos uma nota à caneta, "cartas de Cecília Meireles doadas por mim ao arquivo-museu da Fundação da Casa de Rui Barbosa". Entre as cartas há somente duas escritas por Isabel à Cecília, e mais textos de conferências e aulas que a poeta deu na Universidade do Brasil, em 1937. Além do material da própria Isabel do Prado, como crônicas, traduções e roteiros de seus programas de rádio,

\footnotetext{
${ }^{2}$ Cf:: Cristovão, 1982, Lâmego, 1996. Gouvea, 2001. Oliveira, 2001. Pimenta, s/d: neste artigo a autora apresenta a localização das correspondências mais conhecidas de Cecília e os acervos onde estão localizadas.
} 
que são, também, uma mostra da profunda troca intelectual, artística e de amizade entre as duas.

Isabel do Prado leu e traduziu poemas de Cecília Meireles para a BBC de Londres nos anos $1940^{3}$. Sob o pseudônimo Patrícia Campos, escreveu crônicas e reportagens que expressavam principalmente suas reflexões sobre a Guerra. Foi a primeira mulher a ser contratada pelo serviço brasileiro da BBC (Leal, 2008). Seu programa radiofônico era transmitido para o Brasil da Inglaterra, um dos centros do conflito durante a Segunda Guerra Mundial. A relação das crianças e das mulheres britânicas com a Guerra foi tema das crônicas que leu em 1943 na Rádio Roquete Pinto, no Rio de Janeiro. Em 1945 foi para a Alemanha, contratada pela United Nations Relief and Rehabilitation Administration (UNRRA) para dar apoio aos refugiados da Guerra. Nessa época a correspondência com Cecília foi interrompida, e retomada no ano seguinte, quando Isabel foi trabalhar no Departamento de Educação da UNESCO, em Paris, onde permaneceu até 1951, quando então retornou ao Brasil.

À amiga, Cecília dedicou o poema "Canção de remar" (Vaga música), lido por Isabel em um de seus programas da $\mathrm{BBC}$, e que nos remete àquele momento de torpor e "alguma esperança" latentes em tempos de guerra:

\author{
Doce peso \\ desta sonolência, \\ leve cadência \\ de amor e desprezo. \\ Lua mansa, \\ pedaço perdido \\ do anel partido \\ de alguma esperança (...)
}

Isabel teve a preocupação de fazer anotações e organizar seu arquivo de memórias da amiga Cecília, enviando uma parte à Fundação Casa de Rui Barbosa e outra ao Real Gabinete Português de Leitura, também no Rio de Janeiro. Neste, cujas doações datam dos anos 1980, encontramos livros com os quais Cecília presenteou Isabel. Entre eles estão as primeiras edições de $O$ espírito vitorioso, tese que Cecília apresentou ao concurso para professor da Escola Normal, e da antologia Poetas Novos de Portugal, cuja dedicatória mostra o compromisso amoroso que Cecília tinha com seu trabalho e os laços afetivos que as uniu: "Para Isabel do Prado, estes poemas que escolhi com amor".

O carinho de Cecília por Isabel se manifestava sobretudo pelo incentivo que dava à amiga em suas investidas artísticas. Dizia que ela devia aproveitar a rica experiência do que viveu, ainda mais por ter acompanhado tão de perto os episódios da Segunda Guerra.

$\mathrm{Na}$ carta de 20 de fevereiro de 1947 (carta 7), Cecília cobra da amiga o livro que ela prometera fazer sobre a romancista Amandine-Aurore-Lucile Dupin, que escrevia sob o pseudônimo de George Sand. Musa, pintora e autora de romances socialistas no romantismo francês do século XIX, Sand foi amante de Chopin e teve em Dostoievski um de seus leitores

\footnotetext{
${ }^{3} \mathrm{Na}$ reprodução de um dos programas gravado ao vivo e transmitido em português pela BBC, após fazer uma pequena apresentação biográfica de CM, Isabel lê poemas de um de seus primeiros livros, Nunca mais e Poemas dos poemas, e encerra com "Balada a Philip Muir", a saga do copeiro inglês, "Nem Almirante, nem corsário" que atravessa o Atlântico em plena tragédia da Guerra:

“(...) Do lado do norte, há sangue nas águas do oceano.

$\mathrm{E}$ do lado do leste. E nas terras. Sangue inglês.

E, por baixo do mar, andam as sombras sem passos...

Philip Muir, no meio do desastre humano,

serve champanhe, hoje. Amanhã, seu sangue, talvez (...)"
} 
mais devotos ${ }^{4}$. Nesta mesma carta, Cecília fala sobre a importância do "testemunho da experiência", revelando assim o valor que tinha para ela mesma uma escrita produzida a partir de acontecimentos da própria vida. É mais um indício da relação intrínseca entre ficção, poesia, autobiografia e a escrita das cartas, sendo cada uma, a seu modo, expressão das experiências de uma vida.

Tanta coisa que V. poderia fazer, Isabel, com um pequeno impulso... Suas experiências são tão grandes, naturalmente tão ricas, e é tão necessário sempre $\underline{\mathrm{o}}$ testemunho da experiência!... Agora, que os dias não são do mesmo modo tensos, V. nos poderia contar muitas coisas. Eu bem sei que não seriam coisas animadoras. Mas não é isso também que lhe pedimos. No meio de tantas vidas e tantas mortes, V. decerto representa um episódio humano digno de ser narrado (carta 7 - Rio, 20 de fevereiro de 1947).

O livro sobre George Sand não deixou de ser apenas uma ideia, mas o entusiasmo com o potencial artístico da amiga Isabel continuou animando Cecília. Em um momento Isabel começou a pintar, e mantinha interesses diversos, o que Cecília via como uma virtude:

Prefiro a sua dispersão, levada por interesses múltiplos, renovados, incansáveis, que esta direção certeira em que vejo perderem-se tantas criaturas, que, pelo desejo de glória, nada fazem do que conduz a glória, mas apresentam todo esse caminho, e até a própria glória (carta 40 - Rio, 4 de agosto de 1948).

E ao saber que Isabel começara a pintar, Cecília não poupou entusiasmos. Em diversos momentos da correspondência lemos, primeiro, a curiosidade da poeta em relação ao que Isabel estaria pintando e, em cartas posteriores, os comentários de incentivo e os elogios aos quadros produzidos pela amiga.

Gostaria de ver as suas pinturas, mesmo com esse pessimismo todo que $\mathrm{V}$. acrescenta à notícia. Quem sabe V. não está com uma vocação adormecida, "encolhida", como tantas vezes a vejo encolher-se sobre um assunto? (carta 11- RJ, 14 de abril de 47).

Nesta carta, Cecília aconselha Isabel a procurar a pintora Maria Helena Vieira da Silva $^{5}$, mulher do desenhista Arpad Szènes, que desenhou vários retratos de Cecília. O casal mantinha relação de intensa amizade com a poeta, que se refere à Maria Helena como uma mulher difícil, mas demonstra grande admiração por seu trabalho:

Já esteve com Maria Helena? Não creio que ela seja capaz de estimular vocações: é muito impaciente e alheia. Mas, independente do seu feitio pessoal, a obra que realiza tem um grande poder poético; é inspiradora (Idem).

Alguns meses depois, Cecília conta da felicidade que sentiu quando soube a opinião de Maria Helena sobre a nova atividade de Isabel.

Maria Helena - e ela é terrivelmente difícil - dizia-me que V. estava pintando "como um homenzinho honesto". Fiquei contentíssima ao saber disso com essas palavras (carta 23 - RJ, 3 de dez de 47).

Até que, finalmente, em fevereiro do ano seguinte, Cecília recebe em sua casa a tão esperada encomenda: as pinturas de Isabel. E é enfática em seus elogios.

\footnotetext{
${ }^{4}$ Ver mais em: Kern, 2010.

${ }^{5}$ Sobre a pintora Maria Helena Arpad, ver em Lâmego, 2007.
} 
Seus quadros foram uma festa para os meus olhos. E V. dizia que não tinha palavras "belas e boas". Suas palavras são de cor, Isabel. Sua linguagem está aqui: nestes cavalinhos adoráveis, neste vaso de barro, nestas flores... Compreendo que Maria Helena se tenha entusiasmado. Eu também. Há uma poesia imensa nas suas cores (carta $27-$ Rio, $1^{\circ}$ de fevereiro de 1948).

Cecília diz que o que mais lhe encantou foi o uso do branco nas pinturas de Isabel e compara o trabalho da amiga ao do pintor uruguaio Pedro Figari.

Quando vi, em Montevideo, os quadros de Figari (conhece-os? gosta deles?), enamorei-me dos brancos que encontrava. Perdia-me por dentro deles. Caminhava como em luar. E agora surpreendo brancos em V. E agradeço-lhe essa coincidência. Vou enfeitar toda a casa com seus quadros (Idem).

A série de quadros de Figari sobre o Candombe, ritmo proveniente da África que é parte importante da cultura uruguaia, nos remete às pinturas da própria Cecília, especialmente, em Batuque, Samba, Macumba e ainda no encantamento pelo uso do branco em afinidade com o tema da ausência, tão frequente na poética ceciliana.

Em meio aos comentários entusiastas sobre a pintura de Isabel, Cecília faz um parêntese para dizer do abalo que sentiu quando soube da morte de Gandhi e fala sobre a "Elegia" que enviara à amiga.

(Fiquei tão vencida! Queria escrever uma Elegia grande, mas não sei se terei forças. Logo ao chegar - pois soube do assassinato na cidade - escrevi uma pequena elegia, que lhe mando. É a mistura de tudo que me recordou a morte. A frase em francês foi um oficial de marinha que me disse, uma tarde, não há muito, numa recepção. Sooume estranhamente. E neste momento se levantou por si.) (Idem).

Vejamos um trecho da "Elegia", que inicia justamente com a frase em francês mencionada por Cecília:

Les hommes sont des brutes, madame.

$\mathrm{O}$ vento leva a tua vida toda, e a melhor parte da minha.

Sem bandeiras. Sem uniformes. Só alma, no meio de um mundo

desmoronado.

(Dispersos, 1918-64)

O encantamento pela Índia, que levou Cecília a visitar aquele país na década de 1950 e a dedicar-lhe uma série de poemas, era compartilhado por Isabel, que traduziu para o inglês "Cântico à Índia pacífica" (Poemas escritos na Índia, 1953), escrito por Cecília a pedido da Embaixada da Índia, e também fez sua versão de "Elegia sobre a morte de Gandhi", ambas traduções publicadas no Jornal de Notícias da Índia, em 1 de novembro de 1965 e 1 de janeiro de 1966, respectivamente. "Elegia" chegou a ser traduzido para o hindi, motivo pelo qual Cecília foi convidada a conhecer aquele país ${ }^{6}$.

Ao lermos a crônica "Meus 'orientes", em $O$ que se diz o que se entende, podemos conhecer mais sobre os laços de Cecília com o Oriente: "O Oriente tem sido uma paixão constante na minha vida: não, porém, pelo seu chamado 'exotismo' - que é atração e curiosidade de turistas - mas pela sua profundidade poética, que é uma outra maneira de ser da sabedoria" (Meireles, 1980).

\footnotetext{
${ }^{6}$ Ler mais em: Loundo, Dilip. "Cecília Meireles e a Índia: viagem e meditação poética”. In: Gouvêa, Leila V.B. (org.) Ensaios sobre Cecília Meireles. São Paulo: Humanitas; Fapesp, 2007.
} 
Cecília nos conta sobre sua admiração pelo oriente, que começou na infância, na convivência com as duas pessoas mais importantes em sua formação afetiva e intelectual: a avó Jacinta e a babá Pedrina. A avó falava "em linguagem camoniana": "Cata, cata, que é viagem da Índia!'. Eu ainda não sabia do sentido náutico do verbo 'catar': mas parecia-me que, com aquele estribilho, tudo andava mais depressa, como para uma urgente partida." A babá Pedrina, que "sabia muito do Oriente", fazia chás, contava histórias e canções, mostrava figuras em livros, como a do touro alado, que foi a que mais impressionou Cecília, "durante muito tempo aquele poderoso animal com face humana habitou a minha imaginação infantil, mais sugestivo e misterioso que os príncipes e princesas das histórias de fadas". Havia ainda a antiga bandeja da cozinheira, com desenhos chineses e os mascates que vendiam de porta em porta "alfinetes e pentes, rendas de linho e fitas, sabonetes e cosméticos". Enfim, Cecília se vê mergulhada nesse ambiente oriental, de delicadeza, sabedoria e "profundidade poética":

\begin{abstract}
As senhoras usavam quimonos, as mocinhas se abanavam com ventarolas de seda, leques de marfim rendado, comia-se tanto arroz, tantas "fatias chinesas", falava-se de tanto cetim de Macau e de outras fazendas orientais que era como se as naus dos bisavós continuassem a trafegar por esses mares, e delas recebêssemos diretamente a canela e o cravo dos nossos doces de cada dia (Meireles, 1980).
\end{abstract}

A partir desse diálogo tão particular de Cecília com o Oriente, o que nos propõe o artigo "As rotas do Oriente em CM (uma poesia de interculturalidades)", publicado em $A$ ilha ancestral: Vitorino Nemésio e Cecília Meireles, de Margarida Maia Gouveia, é que há na poesia de Cecília uma poética de interculturalidade, de convergência entre diferentes referências estéticas.

\begin{abstract}
A estética ceciliana é, pois, também ela, uma estética de convergências, de curiosas fusões, recuperando um lirismo ao mesmo tempo distante e próximo, do Oriente e do Ocidente, com uma longa tradição histórica mas reconhecido e assumido universalmente como experiência estética e humana que é. Por isso, o orientalismo de Cecília não é um "orientalismo em estado puro" é antes a sedução perante traços que lhe convinham temperamental e culturalmente e de que ela, como ocidental também era a herdeira (GOUVEIA, 2001, p.161).
\end{abstract}

Segundo a autora, que vê na construção da personagem do mártir, do Tiradentes de Cecília, a figura de Gandhi, Romanceiro da Inconfidencia seria o exemplo síntese dessa perspectiva intercultural, pois nesta obra estariam presentes os cruzamentos de gêneros e de culturas. De gêneros, pois se alinha à tradição do Romanceiro e da épica, quer dizer, somamse à exaltação do herói (característica do épico), a potência narrativa e a carga lírica dos 'romances' tradicionais. Contudo, e aí estaria a interseção de culturas, "ao tratar o herói nacional Tiradentes, Cecília projeta porém nele a sua visão oriental de raiz indiana, do resistente à maneira de Gandhi" (Idem, p.161-162).

Quando Cecília envia à Isabel sua "Elegia", na carta de $1^{\circ}$ de fevereiro de 1948 (carta 27), ela o chama de "pequeno" poema a Gandhi. Diz: "Vou ver se consigo realizar o grande. Uma coisa um pouco épica. Não sei como é, mas sei que é. Está vivendo nas minhas veias. Ainda que o não consiga escrever, nem por isso terá deixado de ser". O interessante é que desde a hipótese de uma relação entre a personagem de Tiradentes e Gandhi e do caráter épico de o Romanceiro estar ligado a um sentido filosófico da existência ${ }^{7}$, podemos pensá-lo como este "poema grande" que Cecília tanto desejou escrever sobre o Mahatma.

\footnotetext{
${ }^{7}$ Conferir o artigo "Da universal inquietude, a propósito da correspondência de Cecília a Armando Côrtes Rodrigues". In.: Gouveia, 2001, p.148. A autora faz uma aproximação entre o Romanceiro da Inconfidência e Mensagem, de Fernando Pessoa, a partir da ideia de que em ambos a matéria histórico-épico recebe um tratamento essencialmente lírico, e da constatação de que Cecília foi leitora de Mensagem, como lemos em uma
} 
Cecília frequentou a cidade de Ouro Preto com o objetivo de recolher material para sua pesquisa da peça que pensava em escrever sobre a Inconfidência, o que mais tarde veio a ser o Romanceiro da Inconfidência: "Depois de amanhã iremos a Ouro Preto, por uns dez dias. Se tudo correr bem, verei se posso, afinal, acabar de construir a já famosa peça da Inconfidência" (carta 27 - Rio, $1^{\circ}$ de fevereiro de 1948).

Nesse momento, da criação de o Romanceiro, todas essas referências tão importantes para Cecília estão misturadas: a relação com o Oriente, com a tradição oral das poesias portuguesa e espanhola, o desejo de escrever dramaturgia (em especial a tragédia) e seu interesse pelos personagens da Inconfidência mineira. Para Cecília esse foi um dos grandes episódios da História do Brasil.

$\mathrm{Na}$ carta de 9 de junho de 1947 (carta 13) ela se refere à Inconfidência como "o único fato verdadeiramente trágico em toda a história do Brasil." E, pouco tempo depois, em 17 de julho de 47 (carta 18), diz: "Não me interessa nem Marília nem Gonzaga nem ninguém. Interessa-me "o caso". É mesmo a meu ver, o único grande caso de DESTINO, na história do Brasil." Ainda nesta carta, Cecília revela seu desejo de fazer um tributo aos mártires: "Tenho esperanças de fazer uma coisa digna dos mártires. E, ademais, é uma espécie de tributo de solidariedade aos poetas sacrificados." Pensemos em García Lorca, Gandhi, e no próprio Tiradentes, homens de ideais que foram vítimas de mortes violentas.

Encontramos na correspondência com Isabel uma espécie de diário de criação de o Romanceiro da Inconfidência. Há nesse "diário" do Romanceiro um espaço de confluência entre crítica, autobiografia e poesia. Cecília participa à amiga, e ao leitor das cartas, as diferentes fases de seu processo de concepção do longo poema que se tornou uma de suas obras de maior relevo.

O interesse pelo teatro e a vontade de escrever dramaturgia fez com que a primeira ideia fosse trabalhar o assunto em uma peça:

Talvez a peça sobre a Inconfidência se chame "Os condenados"- com o duplo sentido de serem réus daquela história e representarem os réus eternos, com e sem culpa, destinados a degredos e mortes por uma arquitetura sombria que ninguém deslinda. Ontem fui ao Museu Histórico e vi os restos da forca de Tiradentes. Aquilo deve ser pau Brasil, não sei: parece toda impregnada de sangue: é horrível (carta 13 - RJ, 9 de junho de 1947).

Em "Fala inicial", poema de abertura do Romanceiro, lemos versos que remetem a esta carta de Cecília, ao tema dos Condenados como réus da história, e a "arquitetura sombria" de seus destinos de "esquecimento e cegueira". Vemos também, nesses versos iniciais, a expressão da dificuldade que foi para a poeta mover-se no tema da Inconfidência:

\footnotetext{
Não posso mover meus passos

por esse atroz labirinto

de esquecimento e cegueira

em que amores e ódios vão:

- pois sinto bater os sinos, percebo o roçar das rezas, vejo o arrepio da morte,

à voz da condenação $(. .$.
}

Impressionava Cecília a tragédia que foi a morte de Tiradentes, condenado à forca por crime de rebelião e traição contra a rainha D. Maria I. E havia o desejo de contar essa

das cartas a Côrtes-Rodrigues. E o que daria ao Romanceiro uma "perspectiva pessoana": "Na obra (Romanceiro...) convergem lirismo, épica, misticismo, na construção do herói cruzam-se a abnegação cristã e o sentido do martiriológico com a visão do herói pacifista e ainda o ideal sabástico, numa perspectiva pessoana." 
tragédia desde a perspectiva dos personagens, o que a motivou inicialmente a escrever dramaturgia. Contudo, apesar da mudança de rumo no projeto inicial, ela manteve no Romanceiro o trabalho de construção dos personagens e o ambiente teatral. É o que vemos por exemplo nos poemas "Cenário", nos Romances III ou Do caçador feliz", IV ou Da donzela assassinada. Este, por exemplo, está construído em primeira pessoa, como se a própria donzela falasse ao público:

\author{
Sacudia o meu lencinho \\ para estendê-lo a secar. \\ Foi pelo mês de dezembro \\ pelo tempo do Natal. \\ Tão feliz que me sentia, \\ vendo as nuvenzinhas no ar, \\ vendo o sol e vendo as flores \\ nos arbustos do quintal, \\ tendo ao longe, na varanda, \\ um rosto para mirar! (...)
}

As cartas à Isabel mostram o longo e árduo processo de pesquisa para a concepção Romanceiro da Inconfidência, ao qual a poeta se dedicou por quase dez anos. Em 9 de junho de 1947 (carta 13), ela agradece a Isabel pelos livros que recebera da amiga e lhe dá notícias de seu trabalho.

\begin{abstract}
O que eu queria conseguir não era o lírico efeito banal dos amores de Gonzaga, nem o episódio terrificante de Tiradentes: mas uma peça que, sendo nacional, fosse absolutamente humana, pelas suas fatalidades, o seu enredo emaranhado de segredos, tendo de um lado os propósitos de cada inconfidente e de outro as consequências ilógicas - como predestinações. Estou apaixonada pelo assunto, e quero utilizar as próprias palavras dos réus, recriando a atmosfera da sua vida naquele fantástico ano de 1789.
\end{abstract}

Tempos mais tarde, Cecília conta que fez um calendário de tudo o que se passou entre 1786 e 1892, mas que não conseguia seguir com o trabalho por conta de suas atividades como professora na Escola de Teatro. "E eu dando lições aos meus pobres alunos da Escola de teatro... Não, isto não pode continuar. Estou louca para me meter embaixo de uma mesa, num porão, onde ninguém me encontre - que me demitam, não me paguem, se danem, mas eu quero pensar é nisto" (carta 25 - RJ, 13 de jan. de 1948).

No início da década de 1940 Cecília esteve bastante envolvida com o Teatro, escreveu peças sob encomenda para companhias como a de Dulcina de Moraes e trabalhou com grupos amadores como Os Comediantes e o Teatro do Estudante Brasileiro ${ }^{8}$. Em 15 de agosto de 1946, ela escreve à Isabel: "Ando muito interessada em teatro, mas não me animo, por enquanto, a uma experiência. Principalmente por falta de tempo para o inevitável fazer e refazer de um principiante no gênero" (carta 5). A poeta conta ainda sobre seu especial interesse pelo teatro de marionetes, que via como uma atividade nova, sugestiva e com forte potencial educativo.

Escrevi muitas peças, o que foi um bom exercício, pois desejava trabalhar em teatro. Mas só pude representar uma, até agora. (...) Mas como êsse exercício consegui criar forças para escrever uma tragédia que andava sonhando e sofrendo. Não sei se será representável. Mas está feita. E isso é bastante. As peças têm, sobre os poemas, esta vantagem: obrigam o autor a deter-se, a ter disciplina. E isso me parece bom. (carta 8 - RJ, 4 de março de 1947).

\footnotetext{
${ }^{8}$ Cf.: Vicenzia, 2006.
} 
Ao comparar a linguagem dramatúrgica com a poética, Cecília exaltava a vantagem que as peças teriam sobre os poemas: "o poema pode-se fazer de pé, andando, em qualquer parte. Mas a peça é preciso sentar, reler o que está escrito, pôr as ideias nos lugares" (Idem). Mais uma vez, lemos nas cartas a profunda conexão entre vida e produção literária. Nesta mesma correspondência, Cecília revela o drama pessoal pelo qual passava naquele momento: a solidão que sentia por viver numa casa grande, e as filhas e o marido passarem a maior parte do tempo fora. Então, a atração pelo teatro vinha não somente pela vantagem da disciplina que as peças teriam sobre os poemas, mas o fato de criar personagens a obrigava a entrar numa dinâmica de criação que lhe trazia um conforto emocional: "ser fulano e beltrano, falar, calar, estar alegre, estar triste, morrer, matar, etc. Creio que isso me ajuda a viver, nesta prisão em que me encontro, sem uma pessoa, sequer, com quem conversar" (Idem). Podemos perceber então que além da dramaturgia, outra linguagem também ocupava o lugar dessa ausência, tomando o lugar de um interlocutor: as cartas, "porque a situação nua e crua é essa que lhe digo: só converso pelo correio, a milhas de distância" (Idem).

Em 16 de fevereiro de 1948 (carta 28) Cecília escreve para Isabel ao regressar de Ouro Preto, conta que visitou a casa do poeta Cláudio Manuel da Costa e sobre a ideia que teve para uma cena que se passaria na sala de jantar. Ela lamenta a má conservação do imóvel e se diz decepcionada pois a casa de Tiradentes havia sido demolida e no terreno fora reconstruído um sobrado onde naquela ocasião funcionava um bilhar. "Tudo é assim macabro em ouro preto" (carta 28).

O cenário de abandono encontrado por Cecília e seu desejo de criar uma cena que aconteceria na sala de jantar da casa de Cláudio Manoel da Costa têm seus reflexos em versos de "Cenário":

\author{
Entre nuvens, colinas e torrente, \\ uma angústia de amor estremecia \\ a deserta amplidão na minha frente. \\ Que vento, que cavalo, que bravia \\ saudade me arrastava a esse deserto, \\ me obrigava a adorar o que sofria? (...)
}

A dificuldade em escrever sobre a Inconfidência se agravou quando a poeta soube que a atriz Carmem Santos estava produzindo um filme, conforme lemos no desabafo à amiga: "Calcule a angústia do meu coração! Agora, o filme está no cartaz, e eu li hoje a primeira crítica, não inteiramente favorável, apesar de tanta propaganda" (carta 32 - RJ, 23 de abril de 1948). Na carta seguinte, Cecília faz uma análise do filme e revela que ele já não é mais um problema: "Nem é tão bom que me impeça de continuar a trabalhar no drama, nem tão ruim como era possível esperar" (carta 33 - RJ, 28 de abril de 1948). Ela critica a falta de homogeneidade na composição das cenas, que seria resultado da excessiva preocupação com a fidelidade histórica que tornou a filmagem demorada e o filme cansativo. "E como o assunto precisa de síntese violenta e clara, e não acharam quem a fizesse, recorreram a uma técnica de "quadros", em lugar de um argumento seguido, desenrolado com ordem" (Idem).

O fato é que Cecília chegou a parar a produção de sua "peça" sobre a Inconfidência por causa do filme:

Calcule V. que se anunciava uma coisa do outro mundo, com a colaboração de toda essa gente sabida de Minas (os historiadores que não mostram senão a alguns privilegiados os arquivos que têm no fundo de gavetas invioláveis e inutilizáveis, compreende?). Eu, que em História sou simplesmente poeta, fiquei desconfiada de que ia sair uma coisa pasmosa, e que a minha peça era desnecessária. Mas não saiu. 
Então, puxei dos meus papeizinhos, e vou ver se continuo (carta 35 - RJ, 10 de maio de 1948).

Cecília escreve à Isabel sobre as leituras que estava fazendo e a angústia de seu processo de criação. "Se V. soubesse o que tenho lido! Todo o século 18, na Espanha, na Itália, em Portugal, na França, no mundo... Isso me impede outras leituras, atrapalha muito a minha vida. Preciso acabar o quanto antes, para ter algum sossego!" (carta 21 - RJ, 4 de setembro de 1947).

Esse processo de idas e vindas é narrado pela poeta no texto que escreveu anos mais tarde, após a versão final de $O$ Romanceiro... "Como escrevi o Romanceiro da Inconfidência" é resultado de uma conferência apresentada por Cecília em 20 de abril de 1955, na Casa dos Contos, em Ouro Preto.

\begin{abstract}
Assim, a primeira tentação, diante do tema insigne, e conhecendo-se tanto quanto possível, através dos documentos do tempo, seus pensamentos e sua fala - seria reconstituir a tragédia na forma dramática em que foi vivida redistribuindo a cada figura o seu verdadeiro papel. Mas, se isso bastasse, os documentos oficiais, com seus interrogatórios e respostas, suas cartas, suas sentenças e defesas, realizariam a obra de arte ambicionada e os fantasmas sossegariam, satisfeitos (Meireles, 1955).
\end{abstract}

O que temos portanto é a relação intrínseca entre a vida e a produção literária da poeta, da qual as cartas podem ser consideradas parte integrante.

\title{
REFERÊNCIAS
}

ANDRADE, Carlos Drummond. Sentimento do Mundo, 1935-40. Obra completa. Rio de Janeiro: Cia. José Aguilar Editora, 1967.

CRISTÓVÃO, Fernando. Cartas inéditas de Cecília Meireles a Maria Valupi. In: Revista Colóquio/Letras. Documentos, n.66, Mar. 1982.

GOUVÊA, Leila V. B. Cecília em Portugal. São Paulo: Iluminuras, 2001.

GOUVEIA, Margarida Maia. A ilha ancestral: Vitorino Nemésio e Cecília Meireles. Portugal: Fundação Eng. António de Almeida. Casa dos Açores do Norte, 2001.

KERN, Daniela. George Sand e a crítica de arte: a passagem do Romantismo ao Realismo na arte francesa do século XIX. Ciências \& Letras, Porto Alegre, n.47, p.63-73, jan./jun. 2010. Disponível em: < http://seer1.fapa.com.br/index.php/arquivos/article/view/39/32 >

LAMEGO, Valéria. Dois mil dias no deserto: Maria Helena Vieira da Silva no Rio de Janeiro (1940-47), 2007. Disponível em: < www.coresprimarias.com.br/ed_10/lamego.pdf >

LEAL, Laurindo. Vozes de Londres: memórias brasileiras da BBC. SP: EdUSP, 2008.

MEIRELES, Cecília. Obra poética. Rio de Janeiro: Cia. José Aguilar Editora, 1967.

. Cartas manuscritas a Isabel do Prado e Alberto de Serpa no acervo da Fundação Casa de Rui Barbosa/ RJ. 
Como escrevi o Romanceiro da Inconfidência. Conferência pronunciada por C.M. na Casa dos Contos. Ouro Preto, 20 de abril de 1955.

OLIVEIRA, Ana Maria Domingues de. Estudo crítico da bibliografia sobre Cecília Meireles. São Paulo: Humanitas, USP, 2001.

VICENZIA, Ida. O teatro poético de Cecília Meireles. Tese de Doutorado. Faculdade de Letras, PUC-RJ, 2006. Disponível em: <

www.maxwell.lambda.ele.puc-rio.br/acessoConteudo.php?nrseqoco=27542>

Recebido em: 29 de janeiro de 2015.

Aceito em: 08 de julho de 2015. 